\title{
Interventions for Primary Caregivers of Children with Autism Spectrum Disorder: A cross-sectional study of current practices of stakeholders in South Africa
}

\author{
*Deborah Leigh Fewster BOT, MPhil in Group Therapy. https://orcid.org/0000-0002-9424-8976 \\ Lecturer, Occupational Therapy Department, UKZN
}

\author{
Catharina Uys BOT, BOT (honours), M (AAC), PHD. https://orcid.org/0000-000 I-9722-994 I \\ Associate Professor, Faculty of Health Sciences, Department of Occupational Therapy, University of Pretoria
}

Pragashnie Govender BOT, MOT, PHD. https://orcid.org/0000-0003-3 I55-3743

Assoc. Professor, Occupational Therapy Department, Academic Leader of Research in School of Health Sciences (UKZN)

Background: Primary caregivers of children with autism spectrum disorder (ASD) face many challenges potentially impacting their mental health and well-being. Given their role in childcare, it becomes essential that primary caregivers be recognised as health care users who should receive interventions towards improved health, well-being and quality of life (QOL). The study aimed to describe the content, structure and mechanism of delivery of interventions offered to primary caregivers of children with ASD, with specific reference to QOL, in South Africa.

Method: A cross-sectional survey design was used to establish the interventions provided to primary caregivers as reported by health care and non-health care professionals who deliver interventions to children with ASD and their families, using an online questionnaire. Snowball sampling was implemented to access a sample of $6 /$ respondents. Demographic data were analysed using descriptive statistics. Details of specific content of interventions were analysed according to identified intervention goals. Closed questions (binary and intensity scales) were analysed using frequencies and means and open-ended questions were thematically analysed with deductive reasoning using QOL domains as identified in relevant literature.

Results: Demographics of respondents are presented. Content of intervention included goals towards, awareness about ASD, interventions beneficial for the child with ASD and interventions beneficial for the primary caregiver. The structure and mechanism of delivery of interventions are described. Three QOL domains, development and activity, as well as social and emotional wellbeing, were more commonly targeted in interventions. Physical and material wellbeing were targeted to a lesser extent.

Conclusion: The QOL elements that are embedded in the described interventions described, highlight both strengths and limitations within current practices. Additionally, it is noted that interventions appear to primarily cater for the needs of the child, with gaps in catering directly for the needs of the primary caregiver. The mental health and wellbeing of the primary caregiver is essential for the child with ASD to develop and achieve their optimal potential. Therefore inclusion of the social, emotional and health needs of the primary caregiver need to be overt with specific outcomes towards improved QOL within interventions.

Key words: primary care givers, quality of life, autism, spectrum disorders, interventions

\section{INTRODUCTION}

Parents or primary caregivers of children with psychiatric disorders, including autism spectrum disorder (ASD) engage in the occupation of caregiving. The occupation of caregiving is however characterised by a high burden of care and decreased quality of life (QOL) $)^{1,2}$.

The primary caregiver has significant influence on the child's occupational participation and wellbeing ${ }^{3}$, therefore it is essential that the health and well-being of the primary caregiver is maintained to manage the stressors that are associated with caring for a child with special needs. This need for support requires focused primary interventions for the primary caregiver as a client $t^{4,5}$. In this paper, the authors describe the content, structure and mechanism of delivery of interventions offered to primary caregivers of children with ASD, with specific reference to quality of life, in the South African context.

\section{LITERATURE REVIEW}

Caregiving as an occupation embodies characteristics of being purposeful and meaningful, contextualised and requiring active engagement ${ }^{6}$. Active engagement in the roles, tasks and routines of caregiving provide purpose and meaning for the primary caregiver as they achieve the goals of caregiving, develop skills, find meaning in life and connect with others ${ }^{7}$. Whilst the occupation of caregiving is laden with meaning and purpose, given that, the involvement of the primary caregiver is known to positively influence the health and well-being of the child with $A S D^{3,7}$, caregiving may be thwart with challenges such as high stress levels and burden of care in a context of stigma and poor access to resources ${ }^{4,8}$. These challenges alongside the role strain placed on the primary caregiver and the tendency to neglect their own health, impact on their overall wellbeing and $\mathrm{QOL}^{4,9-11}$.

With the increased interest in well-being and QOL as outcomes in health care, it is essential that health care professionals understand these concepts to ensure effective interventions for primary caregivers. The concept of QOL is a multi-dimensional concept that relates to the individual's perception of their life and satisfaction and is closest to the concept of health ${ }^{12,13}$. In their study, Pinto et al ${ }^{14}$ reviewed the concepts of well-being and QOL across 
a number of studies. The review revealed that well-being is closely related to psychological dimensions and can be understood in the context of mental health. In their paper, Felce and Perry's review ${ }^{13}$ of QOL studies revealed five domains of QOL, which include social well-being (relationships, social life, family life and community involvement), emotional well-being (spirituality, self-esteem, mental health management, satisfaction and fulfilment), development and activity (household activities, leisure, work, time management), physical well-being (health, personal safety, fitness and mobility) and material well-being (security, access to food, finances, housing, transport, meals, security and possessions) ${ }^{13}$. There is evidence demonstrating that the primary caregiver of a child has a huge influence on the child's occupational participation ${ }^{15}$. For example, the manner in which a child with ASD is cared for at home impacts on the educational, emotional and physical development of that child"'. Conversely, if a primary caregiver has emotional distress, poor health and/or a low level of well-being, they may present with poor caregiving skills that will inevitably impact the child's participation and development ${ }^{16}$. Moreover, vigilance noted in primary caregivers, specifically mothers, is a contributing factor for mental health issues such as anxiety, depression and stress which further lead to an impact on the QOL of the primary caregiver ${ }^{14,17,18}$.

Research findings into caregiving justifies the need for the caregiver to be considered as the 'silent client'4. Alongside the burden of care and decrease in QOL of primary caregivers of children with $\mathrm{ASD}^{2,5}$, these caregivers tend to neglect their own health and are subsequently in need of intervention ${ }^{9,10,11}$. A review of the available literature highlights that interventions for children with ASD are usually intensive and individual in nature catering for the child's needs with secondary benefit to the primary caregiver ${ }^{19,20}$. Historically, interventions for primary caregivers have been a hybrid of parent-mediated and parent support programmes. The outcomes in parent-mediated programmes are to benefit the child with ASD with the primary caregiver learning skills or techniques to affect change in the child's daily life and development ${ }^{21}$. Parent support programmes provide a direct benefit for the parent. In a recent scoping review of parent education and training programmes the most common programme objectives included understanding and learning strategies for communication, socialisation and managing behaviour of the child with ASD, reducing mental health concerns, parental stress and anxiety and decreasing parental isolation through the introduction of informal support between primary caregivers ${ }^{22}$. In occupational therapy and other health care disciplines, the narrative around understanding and catering for the systems around the child, including the wellbeing and health of the primary caregiver, is as important as providing for the needs of the child ${ }^{23}$. It thus becomes imperative that the care of the primary caregiver becomes an essential component of interventions as the well-being of the primary caregiver results in better overall well-being of the child with ASD.

\section{METHODS}

\section{Study Aim}

This study aimed at describing the content, structure and mechanism of delivery of QOL interventions offered to primary caregivers of children with ASD in the South African context, through a questionnaire completed by stakeholders providing services for this population.

\section{Study Design and Tool Development}

A cross-sectional survey design was followed. An online questionnaire was constructed based on literature reviewed, and themes emanating from a scoping review on QOL interventions for primary caregivers of children with ASD ${ }^{24}$. A total of 44 questions were divided into four sections namely, a) contextual information, b) content of intervention with primary caregivers of children with ASD, c) structure of intervention delivery, and d) mechanism of intervention delivery. Questions included binary response questions, intensity scales such as Likert scales, and open-ended questions. As the snowball sampling method was used to recruit respondents, it was not guaranteed that a respondent would meet the inclusion criteria. A question on whether the respondent offered interventions to the primary caregiver of children with ASD was therefore posed to ensure that this inclusion criterion was met. A negative response automatically directed the respondent to the last section of the questionnaire.

\section{Sampling}

In the management of a child with ASD, a team approach is needed ${ }^{15}$. These teams include health care and non-health care professionals, educators and primary caregivers of children with ASD. In this study, respondents were targeted based on their experience and knowledge in the field of ASD. All respondents were individuals who provide interventions for primary caregivers of children with ASD as per the inclusion criteria for participation in the study. As the study was exploratory in nature, potential respondents were accessed via purposive snowball sampling. As an entry point, a list of potential respondents was developed by the first author. The list was inclusive of authors in the field of ASD in the country, names of presenters from specific conferences that covered ASD, two non-profit organisations, a principal from a Learners with Special Education Needs (LSEN) School, a paediatric neurologist from the department of health, a lecturer at a local university and an occupational therapist in private practice. An invitation to participate in the research with a link to the questionnaire was emailed to the entry point list inviting them to participate and to distribute to those they felt may be able to contribute.

\section{Data management and analysis}

The questionnaire was managed using on online survey management system ${ }^{25}$ and was open for a period of six months. Respondents were able to email the first author with any queries. Data were extracted from the questionnaires using MS Excel. Demographic data were analysed using descriptive statistics to provide a respondent profile. Qualitative data were extracted verbatim from the open ended questions. The intervention content was analysed thematically according to the goals for intervention as identified by the respondents. Goals were placed in categories linked to similar themes of content covered in the interventions. The intervention content was further analysed through deductive reasoning using pre-coded QOL domains as outlined by Felce and Perry ${ }^{13}$. These domains included (I) physical well-being, (2) emotional well-being, (3) social well-being, (4) development and activity, and (5) material well-being as aforementioned. This analysis indicated which QOL domains were targeted by the various interventions. Quantitative data highlighting the structure and mechanism of delivery of interventions were analysed using MS Excel, and are described using frequencies and percentages of these variables. Tabulations and graphical representation was provided where necessary.

\section{Ethical considerations}

Full ethical approval was granted for this study from the Biomedical Research Ethics Committee of the University of KwaZulu-Natal (BE469/16). Informed consent was included in the questionnaire explaining the purpose of the study and that participation was voluntary. To maintain the confidentiality of respondents, access to the questionnaires was password protected. All data were treated as confidential as the questionnaire provided respondents with a unique respondent code. The distribution of the links for the questionnaire were unknown as snowball sampling resulted in anonymity of respondents. Anonymity was ensured as a number was assigned to each respondent.

\section{RESULTS}

The interventions that are offered to primary caregivers of children with ASD in South Africa are described according to their content, structure and mechanism of delivery. Furthermore, the content of interventions are described against $\mathrm{QOL}$ domains ${ }^{13}$. 


\section{Profile of respondents}

The sample size was $n=6 I$. Respondents hailed from private practices $(n=23)$, Department of Health facilities $(n=18)$, non-profit organisations $(n=18)$, Department of Education facilities $(n=14)$, higher education groups/organisations $(n=6)$ and a business entity $(n=I)$. Thirty-eight respondents indicated that they provided interventions for primary caregivers of children with ASD. These respondents included a business entity, a researcher, a behaviour therapist, a principal of a school, educators, a speech therapist, occupational therapists, counselling psychologist, paediatric neurologist and regional development officers from a non-profit organisation. Of the remaining twenty-three questionnaires, $n=22$ were incomplete and $n=I$ being invalid for analysis as it was completed by a respondent who did not provide services to primary caregivers of children with ASD.

\section{Profile of the primary caregivers of children with ASD receiving intervention as indicated by respondents}

Interventions were provided to biological mothers $(n=36)$, biological fathers $(n=33)$, grandparents $(n=26)$, extended family members $(n=18)$, step parents $(n=16)$, adoptive parents $(n=14)$ and siblings $(n=14)$. The age of the children with ASD to whom services were rendered by the respondents ranged between 3-4 years $(n=26)$, $5-6$ years $(n=31), 7-9$ years $(n=33)$, and $10-13$ years $(n=18)$.

\section{Profile of the teams involved in providing interventions for the primary caregivers of children with ASD}

In the questionnaire, respondents were asked whether they worked in a team or independently. The results indicated that multidisciplinary teams (MDT), ranging from two to four members, were involved in the provision of interventions for primary caregivers of children with ASD. Furthermore the questionnaire required the respondents to identify the professions represented in their teams as well as the responsibilities within their specific context. The types of professionals and specific responsibilities were extracted from the data to provide an overview of the team structures as presented by this sample. Table I below provides an outline of the various professionals and responsibilities of each within the teams represented as highlighted by the respondents in this study.

\section{Intervention Content}

Respondents were asked to outline the intervention content in the programmes they offered to primary caregivers in the form of goals of intervention. Through thematic analysis, three goals were extracted from the data. Goals towards awareness about ASD included education and creating awareness about the diagnosis of ASD, provision of resources, and modifications to the home environment. Intervention goals beneficial for the child with ASD included teaching the primary caregiver skills and strategies to help their child reach independence in activities of daily living, communication, socialisation and play; how to engage meaningfully with their child at home for optimal development in sensory, play, gross motor and fine motor development; providing knowledge on keeping a safe home environment for the child and provide skills to manage behavioural difficulties with the child with ASD. Intervention goals beneficial for the primary caregiver included provision of stress management skills, developing relationships with other primary caregivers in order to provide ongoing support and a means to assist them in accepting the diagnosis of ASD; providing opportunities to network with other primary caregivers of children with ASD; empower and enable primary caregivers to become advocates for their child with ASD to help them reach their full potential, provide support and hope for primary caregivers and families of children with ASD.

The three intervention topics namely awareness of ASD, intervention beneficial for the child with ASD and intervention beneficial for the primary caregiver are outlined in Table II (pages 44/45) according to the mechanism of delivery/activity used in the interventions, specific topics covered and QOL domains targeted in the interventions.

The development and activity QOL domain featured prominently in the interventions provided. The emotional and social wellbeing domains were evident when the intervention provided for the primary caregiver directly thereby catering for their needs and challenges in raising a child with ASD. These three QOL domains are further illustrated in Figure I (page 46.) showing the sub-categories of the five QOL domains. Household activities $(n=20)$ and time management $(n=17)$ under the development and activity domain of QOL were examples that were covered in the interventions. Under the social wellbeing QOL domain, relationships $(n=28)$ and social life $(n=25)$ were most prominently catered for in interventions. Self-esteem $(n=20)$ and stress management $(n=18)$ under the emotional wellbeing QOL domain were most frequently catered for in the interventions for primary caregivers. The QOL domains of physical and material

Table I: Responsibilities of the MDT involved in primary caregiver interventions

\begin{tabular}{|l|l|}
\hline \multicolumn{1}{|c|}{ Team member } & \multicolumn{1}{c|}{ Responsibilities } \\
\hline Medical practitioner & Prescription of medication, referral to other MDT, health maintenance. \\
\hline Psychiatrist & Prescription of medication, assessment of child with ASD. \\
\hline Psychologist & $\begin{array}{l}\text { Assessment and therapy, family support and guidance, mental health management of the primary caregiver, } \\
\text { behaviour management, counselling, parenting skills, stress management, coping strategies, psychological needs } \\
\text { of the primary caregiver and child with ASD. }\end{array}$ \\
\hline Occupational Therapist & $\begin{array}{l}\text { Primary caregiver training, teaching new skills, provision of home programmes, training in activities of daily } \\
\text { living, behavior management, social interaction, gross motor intervention, fine motor skills, visual perception, } \\
\text { concentration, assessment in developmental delays, development of play, block therapy, dealing with sensory } \\
\text { difficulties, toilet training. }\end{array}$ \\
\hline Speech Therapist & $\begin{array}{l}\text { Communication and use of AAC, training of staff in the use of communication systems, education of primary } \\
\text { caregivers, social skills intervention, developing expressive and receptive language skills, feeding. }\end{array}$ \\
\hline Physiotherapist & Physical development, fitness, physical exercises. \\
\hline Social Worker & $\begin{array}{l}\text { Screening, referral to non-governmental organisations, school placement, counsellor, mediator, parental support, } \\
\text { grants, social needs management, resource assistance, housing, family relations. }\end{array}$ \\
\hline Educator & Teaching literacy and numeracy, classroom support. \\
\hline Headmistress & $\begin{array}{l}\text { Support system for primary caregivers, staff training to improve interactions with and support for the primary } \\
\text { caregiver. }\end{array}$ \\
\hline Facilitators/au pair/tutor & $\begin{array}{l}\text { Overseeing afternoon activities (homework and therapy programmes), providing support for the child with ASD } \\
\text { and teacher in the classroom, and assisting with specific school subjects, building confidence in the child with ASD. }\end{array}$ \\
\hline
\end{tabular}




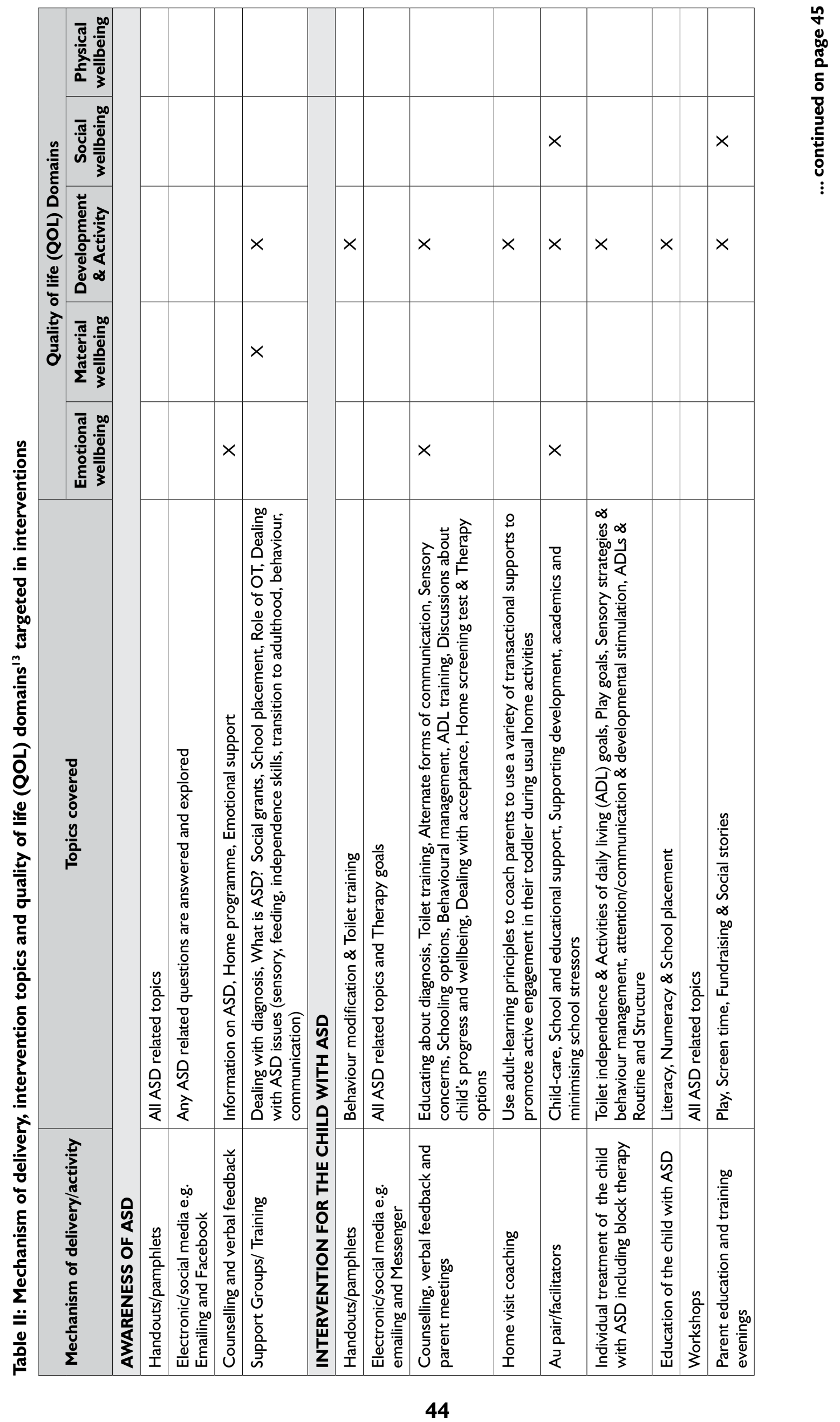




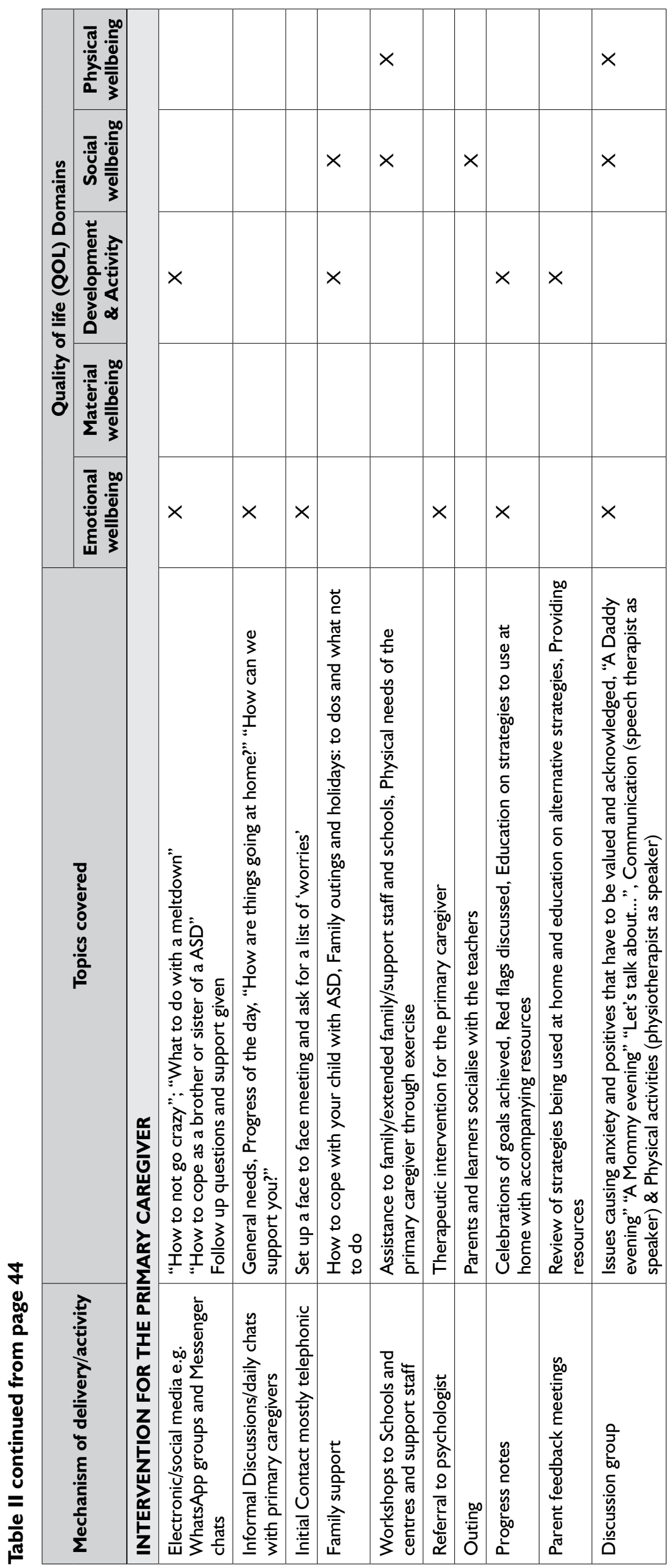

wellbeing as defined by Felce and Perry ${ }^{13}$ featured less in the interventions for primary caregivers.

\section{Intervention structure and mechanism of delivery}

In this study, structure and mechanism of delivery refers to how an intervention is presented, what resources are offered as well as the format of the intervention. Format relates to how the intervention is set out and arranged. Individual sessions appeared to be the most frequently used format to deliver intervention for the primary caregiver $(n=29)$. Of these, the frequency of intervention on an individual basis were noted as follows: "as the need arose' $(n=10)$; 'weekly' $(n=7)$; 'monthly' $(n=6)$; 'fortnightly' $(n=3)$ and 'daily' $(n=3)$. The respondents chose the option of 'as the need arises' more frequently to describe how often a certain type of format was used. For example the following formats 'in a therapy group' $(n=6)$, 'in a support group' $(\mathrm{n}=\mathrm{II})$, 'telephonic conversation' $(n=17)$, 'via email ' $(n=I I)$, 'via sms' $(n=12)$, 'pamphlets' $(n=16)$ and 'awareness days' $(n=15)$ were chosen by respondents as an appropriate format 'as the need arose'.

The three most commonly used methods of delivery included verbal presentations $(n=23)$, reading from handouts $(n=16)$ and group discussions $(n=12)$. Techniques used during interventions included face-to-face contact $(n=2 \mathrm{I})$, discussions $(n=2 I)$ and reflection $(n=\mid 3)$. Twenty-one respondents provided handouts to primary caregivers as a resource. The most popular social media used to communicate with primary caregivers was WhatsApp $(n=24)$ and Facebook $(n=20)$.

Further elements explored in the format of interventions included the frequency (contact sessions), duration (length of total intervention offered) and contact duration (per session) which are illustrated in Table III (page 46). Eight respondents had fortnightly contact with primary caregivers during their intervention, four respondents' interventions lasted for 12 weeks and ten respondents indicated duration of contact as 60 minutes.

\section{DISCUSSION}

Caregiving can be a stressful occupation for primary caregivers of children with ASD. However, there is evidence to support the notion that primary caregivers can have a positive influence on the occupational participation of a child with ASD'. Within health care, the narrative around understanding the wellbeing and health of the primary caregiver, is as important as providing for the needs of the child ${ }^{2,8}$

In this paper, the authors described the quality of life interventions for primary caregivers of children with ASD within the SA context. Traditionally, the focus of ASD interventions has been on the child, with the primary caregiver's health, wellbeing and QOL being secondary or completely overlooked as part of the holistic management of the child ${ }^{9,10,11,21}$.

It is evident from the results that the respondents in this study provided interventions beyond the traditional interventions as stated above and have included the primary caregiver in the holistic management (including QOL) of the child with ASD. 


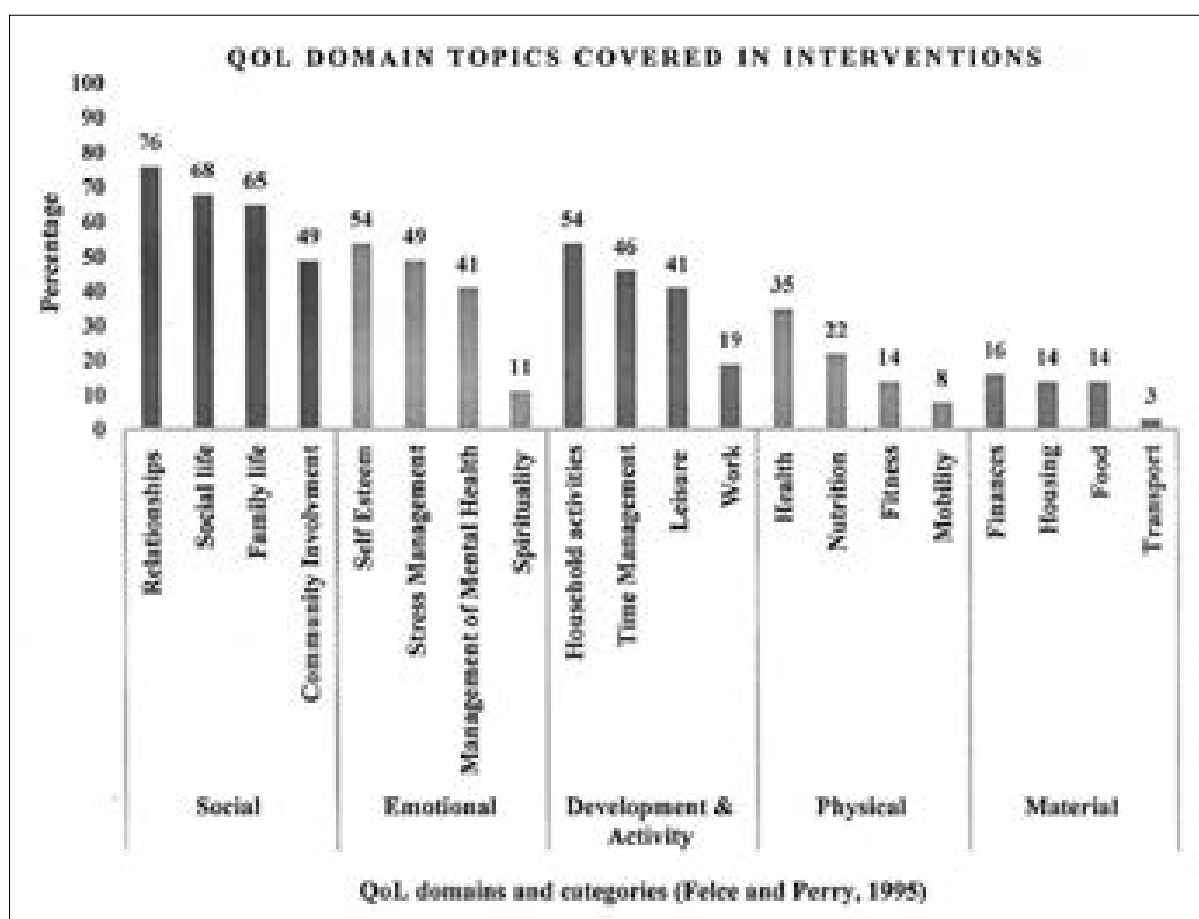

Figure I: Quality of Life domains ${ }^{13}$ covered in the interventions for primary caregivers

Interventions described in this study were provided for the extended family. They were geared primarily towards the biological mothers and fathers, although a large percentage of respondents provided interventions for grandparents, extended family members and siblings. The nature of ASD compels family members to step in

Table III: Frequency, duration and length of contact of interventions provided to primary caregivers of children with ASD

\begin{tabular}{|c|c|c|}
\hline & & NUMBER (\%) \\
\hline \multirow{8}{*}{$\begin{array}{l}\text { FREQUENCY OF } \\
\text { CONTACT }\end{array}$} & Daily & $6(24 \%)$ \\
\hline & Weekly & $7(28 \%)$ \\
\hline & Fortnightly & $8(32 \%)$ \\
\hline & Monthly & $4(16 \%)$ \\
\hline & 3-Monthly & $2(8 \%)$ \\
\hline & 6-Monthly & I (4\%) \\
\hline & As required & 7 (28\%) \\
\hline & Once off & $3(12 \%)$ \\
\hline \multirow{6}{*}{$\begin{array}{l}\text { DURATION OF } \\
\text { INTERVENTION }\end{array}$} & 12 weeks & $4(16 \%)$ \\
\hline & 12 months & $5(20 \%)$ \\
\hline & Fortnightly for 3 months & $3(12 \%)$ \\
\hline & 3 hours once a week & $3(12 \%)$ \\
\hline & Once off & $4(16 \%)$ \\
\hline & As required & 17 (68\%) \\
\hline \multirow{8}{*}{$\begin{array}{l}\text { LENGTH OF } \\
\text { CONTACT }\end{array}$} & $15-20$ minutes & $7(28 \%)$ \\
\hline & $30-45$ minutes & $7(28 \%)$ \\
\hline & 60 minutes (I hour) & $10(40 \%)$ \\
\hline & 90 minutes ( 1.5 hours) & $3(12 \%)$ \\
\hline & 2-4 hours & $9(36 \%)$ \\
\hline & I day & I (4\%) \\
\hline & 2 days & I (4\%) \\
\hline & As required & $5(20 \%)$ \\
\hline
\end{tabular}

to share the burden of care with the biological mothers and fathers, often becoming the primary caregiver themselves, depending on the parents' work responsibilities and ability to cope ${ }^{26,27}$. Studies confirm the need to provide interventions for the entire family due to the pervasive effects and burden of ASD on the family resulting in an overall decrease in family wellbeing ${ }^{28,29}$.

Multidisciplinary teams were responsible for providing interventions to primary caregivers in this study as opposed to input from one professional source. Children with ASD have special health needs, therefore requiring specialised attention and care ${ }^{30}$. Primary caregivers also require this type of care. The educational, medical, allied health, and social work professionals provide specialised interventions for the primary caregiver, as indicated in this study, which appears to be in keeping with international studies presenting the need for this team profile ${ }^{22,30}$.

The interventions offered to primary caregivers of children with ASD within SA seem to be in keeping with international standards as noted in a scoping review conducted by the authors ${ }^{24}$. Awareness of ASD was a theme extracted from the intervention content which included education about the diagnosis and resources about the condition. Education and awareness provides an essential guideline for management of the child with ASD as the primary caregiver deals with the daunting process of diagnosis ${ }^{31,32}$ is well known that delayed diagnosis and poor understanding complicates and delays the management of the child with $\mathrm{ASD}^{33}$. Educating the primary caregiver at this point is vital, as the child with ASD requires early intervention for optimal functional outcomes ${ }^{34}$.

Interventions to benefit the child with ASD included content that focussed on providing the primary caregiver with skills to manage the child with ASD in relation to activities of daily living, fostering development in communication, play and education, and teaching the primary caregiver strategies to manage the child's behaviour. The typical presentation of a child with ASD includes deficits in reciprocal social interaction alongside impaired communication with resisted, repetitive and stereotypical movements and behaviour ${ }^{29}$. This presentation in the child with ASD dictates the areas that require intervention directly with the child with ASD and the nature of skills required by the primary caregiver. The aspects of communication, behaviour and social engagement are needed to function effectively in areas of occupation hence the focus of intervention for the child with ASD was noted in the literature review.

The results obtained in this study regarding interventions for the primary caregiver were closely linked to the child with ASD with little focus on the direct needs of the primary caregiver. A child's diagnosis of ASD has an impact on the family therefore it becomes difficult to separate the child's intervention from the intervention provided to the primary caregiver ${ }^{35}$. The primary caregiver's psychological well-being is vulnerable resulting in a risk of developing mental illness as they juggle all the demands of caregiving amidst other roles. Caregiving may be seen as imposed upon the parent who often sacrifices their occupational choices for the benefit of their child with ASD and/or family 4 . Primary caregivers who possess good health and have a sense of wellbeing may provide more optimal parenting that affords the child with ASD a better opportunity to reach their full potential through occupational participation ${ }^{36}$.

Primary caregivers cope over time and their needs in relation to their child with ASD fluctuate depending on the child's developmental stage. These needs may taper off as the child gets older ${ }^{37}$. Regardless of the child's stage of development the primary caregiver is an integral part of the child's life; therefore their health, well-being 
and QOL needs to be overtly recognised and addressed in practice. Despite the recognition that the primary caregiver is key to the care of the child with ASD, it is noted from this study that the focus of intervention is mostly to benefit the child. Besides the inclusion of child related interventions, the needs of primary caregivers should also be understood in order to receive the relevant support for a better QOL.

The QOL domains targeted in the interventions for primary caregivers in this study were development and activity, social wellbeing and emotional well-being. The domain of development and activity is concerned with the acquisition of skill in order to achieve competence or independence in activities such as work, leisure, housework and education ${ }^{13}$. The focus on occupational participation, attainment of skill and fostering independence in a range of activities within the interventions provided for primary caregivers may account for the propensity of this domain.

In the context of the child with ASD, social and emotional well-being relates well to the presentation of ASD. Social support is a mediating factor in the psychological well-being of the primary caregiver of a child with ASD in that if social support is absent the mental health of the primary caregiver declines ${ }^{36,38}$. Moreover, participation in social activities provides an important coping strategy in mothers of children with ASD ${ }^{39}$. Within this study social well-being was addressed by providing intervention to improve relationships, social life and family life which is related to the stressors expressed by primary caregivers such as difficulties with family members, stigma and managing their daily lives with the child with ASD ${ }^{15,16}$. Self-esteem was the aspect that most respondents targeted in the domain of emotional well-being within their interventions with primary caregivers. This links well with the literature that states that primary caregivers lack confidence in their efficiency as caregiv$\mathrm{ers}^{38}$. Gaps noted in the interventions provided in this study within the domain of emotional well-being were stress management and management of mental health. These two aspects need to be explicit outcomes within an intervention for primary caregivers as there is evidence that primary caregivers report high levels of stress and mental health difficulties ${ }^{2,5}$.

The QOL domains of physical and material wellbeing were less evident in the interventions. Evidence has shown that physical activity and fitness, noted in the physical wellbeing QOL domain, has a positive impact on emotional wellbeing ${ }^{40}$. Material wellbeing should be considered especially given the financial strain and burden primary caregivers struggle with daily in raising a child with ASD ${ }^{41}$. The definition of health according to The World Health Organization (WHO) is that it is a state of complete physical, mental and social wellbeing and not merely the absence of disease ${ }^{42}$. Therefore it is important to consider the inclusion of all the QOL domains within interventions in an attempt to improve the health and wellbeing of primary caregivers.

\section{LIMITATIONS OF THE STUDY AND FUTURE RECOMMENDATIONS}

The limitation of this study was that data were accessed from respondents who provided interventions for primary caregivers of children with ASD and not from the primary caregivers who received interventions. There is also sampling bias given the sampling strategy used in this study. Given the limited knowledge about interventions offered to primary caregivers in SA, research exploring the perceptions of primary caregivers in relation to services they received would be valuable in the future.

\section{CONCLUSION}

This paper described the interventions provided to primary caregivers of children with ASD from a cross-sectional survey of service providers in South Africa. The interventions appear to primarily cater for the needs of the child, with gaps in catering directly for the needs of the primary caregiver. Given that the mental health and well-being of a primary caregiver is essential for the child with
ASD in developing and achieving their optimal potential, interventions targeting the social, emotional and health needs of the primary caregiver need to be overt with specific outcomes towards improved QOL for these primary caregivers. The paper provides a point of departure from which interventions for primary caregivers of children with ASD may be planned and implemented towards improving their overall QOL needs.

\section{REFERENCES}

I. Franz L, Chambers N, von Isenburg M, de Vries PJ. Autism spectrum disorder in Sub-Saharan Africa: A comprehensive scoping review. Autism Research. 2017; 10(5): 723-749.

https://doi.org/10.1002/aur. 1766

2. Perez Algorta G, MacPherson HA, Youngstrom EA et al. Parenting Stress Among Caregivers of Children With Bipolar Spectrum Disorders. Journal of Clinical Child \& Adolescent Psychology. 2018; 47(I): 306-320. https://doi.org/10.1080/15374416.2017.1280805

3. Bruder MB. Family-centered early intervention clarifying our values for the new millennium. Topics in Early Childhood Special Education. 2000; 20(2): 105-II5. https://dx.doi.org/ I0. I |77/027 I I 2 | 40002000206

4. Gurayah T, Govender P, Naidoo D, Fewster DL, Lingah T. Faces of caregiving in a South African context. In: Occupational therapies without borders integrating justice with practice, London: Elsevier, 2017: 373-380, ISBN 978-0-7020-5920-9.

5. Salomone E, Leadbitter K, Aldred $\mathrm{C}$ et al. The association between child and family characteristics and the mental health and wellbeing of caregivers of children with autism in mid-childhood. Journal of autism and developmental disorders. 2018; 48(4): I I89-I 198. https://doi.org/10.1007/s 10803-017-3392-x

6. Molineux $M$. The nature of occupation. In: Occupational therapy and physical dysfunction enabling occupation, London: Elsevier, 2010: 17-26

7. Law M. Participation in the occupations of everyday life, Distinguished Scholar Lecture. American Journal of Occupational Therapy. 2002; (56): 640-649.

https://doi.org/10.5014/ajot.60.6.627

8. Pinquart M. Parenting stress in caregivers of children with chronic physical condition-A meta-analysis. Stress and Health. 2018; 34(2): 197-207.

https://doi.org/10.1002/smi.2780

9. Brehaut JC, Kohen DE., Raina P. The health of primary caregivers of children with cerebral palsy: how does it compare with that of other Canadian caregivers? Pediatrics. 2004; I|4(2): el82-el9l. https://doi.org/10.1542/peds. I 14.2.el 82

10. Hunt CK. Concepts in caregiver research. Journal of nursing scholarship. 2003; 35(I): 27-32. https://doi.org/ I0. I I I I/j. I547-5069.2003.00027.x

II. Walker J, Wilkins A, Dallaire J, Sandler H, Hoover-Dempsey K. Parental involvement: Model revision through scale development. The Elementary School Journal. 2005: 106(2): 85-104. http://doi.org/10.1086/499193

12. World Health Organisation (2019) Constitution of WHO: principles. Available at: https://www.who.int/about/mission/en/ (accessed 28 February 2019).

13. Felce D, Perry J. Quality of life: Its definition and measurement. Research in developmental disabilities 1995; 16(I): $51-74$. http://doi.org/10.1016/089|-4222(94)00028-8

14. Moroz A. Exploring the factors related to Pinto S, Fumincelli L, Mazzo A, Caldeira S, Martins JC. Comfort, well-being and quality of life: Discussion of the differences and similarities among the concepts. Porto Biomedical Journal. 2017; 2(I):6-12. http://doi.org/10.1016/j.pbj.2016.11.003

15. Moroz A. Exploring the factors related to parent involvement in the interventions of their children with autism. Masters Thesis 2015, California State University, Sacramento. URI: https://hdl.handle.net/I02 I I .3/I 39987

16. Larson E. Ever vigilant: maternal support of participation in daily life for boys with Autism. Physical and Occupational Therapy in Paediatrics. 2010; 30(1): 16-27.

http://doi.org/10.3109/01942630903297227 
17. Brookman-Frazee L, Stahmer A, Baker-Ericzen MJ, Tsai K. Parenting Interventions for Children with Autism Spectrum and Disruptive Behavior Disorders: Opportunities for Cross-Fertilization. Clinical Child Family Psychol Rev. 2006; 9(3-4): I8I-200.

https://doi.org/10.1007/s 10567-006-0010-4

18. Dardas LA, Ahmad MM. Quality of life among parents of children with autistic disorder: A sample from the Arab world. Research in Developmental Disabilities. 20I4; 35(2): 278-287.

https://doi.org/10.1016/j.ridd.2013.10.029

19. Beaudoin AJ, Sebire G, Couture M. Parent Training Interventions for Toddlers with Autism Spectrum Disorder. Autism Research and Treatment. 20I4; 839890 (20I4): I-I5. http://doi.org//0.1I55/2014/839890

20. Cohn ES. Parent perspectives of occupational therapy using a sensory integration approach. American Journal of Occupational Therapy. 200I; 55(3): 285-294. https://doi.org// 0.5014/ajot.55.3.285

21. Bearss K, Johnson C, Smith T, Lecavalier L, Swiezy N, Aman M, Scahill L. Effect of parent training vs parent education on behavioural problems in children with autism spectrum disorder: A randomized trial. Journal of American Medical Association. 20I5; 313: I5241533. https://doi.org/I0.100I/jama.2015.3150

22. Dawson-Squibb J-J, Davids EL, Harrison AJ, Molony MA, de Vries, PJ. Parent Education and Training for autism spectrum disorders: Scoping the evidence. Autism. 2019. http://doi.org/10.1177//362361319841739

23. Siron NH. "Where's the support?": An Exploratory Study of Supports for Primary Caregivers of Children with Autism Spectrum Disorder in the Toronto Region. Master's Thesis 2015, Wilfrid Laurier University, Canada.

24. Fewster DL, Govender P, Uys CJE, Quality of life interventions for primary caregivers of children with autism spectrum disorder: a scoping review. Journal of Child and Adolescent Mental Health. 2019; 31(2). https://doi.org/10.2989/17280583.2019.1659/46

25. eSurvey Creator.Free online survey creator. Switerland, 2007. https://www.esurveycreator.com (accessed 2018).

26. Margetts JK, Le Couteur A, Croom S. Families in a state of flux: the experience of grandparents in autism spectrum disorder. Child: Care, Health and Development. 2006; 32: 565-574. https://doi.org/I0.1 I I I/j. I365-22 I4.2006.0067I.x

27. Schlebusch L, Samuels AE, Dada S. South African families raising children with autism spectrum disorders: relationship between family routines, cognitive appraisal and family quality of life. Journal of Intellectual Disability Research 2016; 60(5): 4I2-423. https://doi.org/10.1 I I I/jir. 12292

28. Karst JS, Van Hecke AV. Parent and Family Impact of Autism Spectrum Disorders: A Review and Proposed Model for Intervention Evaluation. Clinical Child Family Psychology Review. 2012; 15(3): 247-277.

https://doi.org/I0.1007/s 10567-012-01 I9-6

29. Schlebusch L, Dada S, Samuels AE. Family Quality of Life of South African Families Raising Children with Autism Spectrum Disorder. Journal Autism Developmental Disorders. 2017; 47(7): 1966-1977. https://doi.org/10.1007/s 10803-017-3102-8

30. Dillenburger K, Röttgers HR, Dounavi K et al. (2014). Multidisciplinary Teamwork in Autism: Can One Size Fit All? The Australian Educational and Developmental Psychologist. 20 I4; 3 I (2): 97-I I 2. https://doi.org/10.1017/edp.2014.13

3I. McStay R, Trembath D, Dissanayake $C$. Stress and family quality of life in parents of children with autism spectrum disorder: Parent gender and the double abcx model. Journal of Autism and Developmental Disorders. 20I4; 44(I2): 310I-3II8.

https://doi.org/I0.1007/s I0803-0|4-2178-7

32. Preeti K, Srinath KD, Seshadri D, Girimaji D, Kommu D. Lost time-need for more awareness in early intervention of autism spectrum disorder. Asian Journal of Psychiatry. 2017; 25: 13-15. https://doi.org/I0.1016/j.ajp.2016.07.021

33. Wang J, Zhou X, Xia W, Sun C, Wu L, Wang J. Autism awareness and attitudes towards treatment in caregivers of children aged 3-6 years in Harbin, China. Social Psychiatry \& Psychiatric Epidemiology. 20I2; 47 (8): I30I-1308.

https://doi.org/I0.1007/s00 I27-0 I I-0438-9
34. William PL, Mandy D, Tony C, Skuse DH. Testing the Construct Validity of Proposed Criteria for DSM-5 Autism Spectrum Disorder. Journal of the American Academy of Child \& Adolescent Psychiatry. 2012; 51 (I): 4I-50.

https://doi.org/10.1016/j.jaac.201 I.10.013

35. Pringle BA, Colpe LJ, Blumberg SJ, Avila RM, Kogan MD. Diagnostic History and Treatment of School-aged Children with Autism Spectrum Disorder and Special Health Care Needs. Centers for Disease Control and Prevention National Center for Health Statistics. 20I2; 92: 2-8. ISSN 194I-4935 (Online ed.).

36. Tomlinson M. Caring for the caregiver: a framework for support. South African Child Gauge 2013: Essential services for young children, PART 2. 20I3: 56-6I.

37. Gray DE. Coping over time: the parents of children with autism. Journal of Intellectual Disability Research. 2006; 50(I2):970-976. https://doi.org/I 0.1 I I I/j.1365-2788.2006.00933.x

38. Kuhaneck HM, Burroughs T, Wright J, Lemanczyk T, Rowntree Darragh A. A Qualitative Study of Coping in Mothers of Children with an Autism Spectrum Disorder. Physical \& Occupational Therapy In Pediatrics. 2010; 30(4): 340-350. https://doi.org/10.3109/01942638.2010.481662

39. Kuhaneck HM, Madonna S, Novak A, Pearson E. Effectiveness of interventions for children with autism spectrum disorder and their parents: A systematic review of family outcomes. American Journal of Occupational Therapy. 2015; 69 (5): I-I4. https://doi.org/10.50I4/ajot.2015.017855

40. Mason P, Kearns A. Physical activity and mental wellbeing in deprived neighbourhoods. Mental Health and Physical Activity. 2013 6(2): $111-117$.

https://doi.org/10.1016/j.mhpa.2013.06.005

4I. ladarola S, Levato L, Harrison B, Smith T, Lecavalier L, Johnson C, Swiezy N, Bearss K, Scahill L, Teaching Parents Behavioral Strategies for Autism Spectrum Disorder (ASD): Effects on Stress, Strain, and Competence. Journal of Autism and Developmental Disorders. 2018; 48:1031.

https://doi.org/10.1007/s10803-017-3339-2

42. World Health Organization (WHO) Constitution of WHO: Principles, 2017.

http://www.who.int/about/mission/en/

\section{AUTHOR CONTRIBUTIONS}

DL Fewster. Primary researcher as PhD candidate. Tool development, recruitment of participants, data collection and analysis, write up of the article.

Assoc. Prof. Uys Supervisor in PhD project and practical input in design of the questionnaire, review and contribution to the article writing.

Assoc. Prof. Govender Supervisor in $\mathrm{PhD}$ project and practical input in concept development, research design, review of the article and writing assistance.

Corresponding Author

*DL Fewster

Email: fewster@ukzn.ac.za 